\title{
Effect of Leak and Breathing Pattern on the Accuracy of Tidal Volume Estimation by Commercial Home Ventilators: A Bench Study
}

\author{
Manel Luján MD PhD, Ana Sogo MD, Xavier Pomares MD, Eduard Monsó MD PhD, \\ Bernat Sales, and Lluís Blanch MD PhD
}

\begin{abstract}
BACKGROUND: New home ventilators are able to provide clinicians data of interest through built-in software. Monitoring of tidal volume $\left(V_{T}\right)$ is a key point in the assessment of the efficacy of home mechanical ventilation. OBJECTIVE: To assess the reliability of the $V_{T}$ provided by 5 ventilators in a bench test. METHODS: Five commercial ventilators from 4 different manufacturers were tested in pressure support mode with the help of a breathing simulator under different conditions of mechanical respiratory pattern, inflation pressure, and intentional leakage. Values provided by the built-in software of each ventilator were compared breath to breath with the $V_{T}$ monitored through an external pneumotachograph. Ten breaths for each condition were compared for every tested situation. RESULTS: All tested ventilators underestimated $V_{T}$ (ranges of $-21.7 \mathbf{~ m L}$ to $-83.5 \mathrm{~mL}$, which corresponded to $-3.6 \%$ to $-14.7 \%$ of the externally measured $\mathrm{V}_{\mathrm{T}}$ ). A direct relationship between leak and underestimation was found in 4 ventilators, with higher underestimations of the $V_{T}$ when the leakage increased, ranging between $-2.27 \%$ and $-5.42 \%$ for each $10 \mathrm{~L} / \mathrm{min}$ increase in the leakage. A ventilator that included an algorithm that computes the pressure loss through the tube as a function of the flow exiting the ventilator had the minimal effect of leaks on the estimation of $V_{T}(0.3 \%)$. In 3 ventilators the underestimation was also influenced by mechanical pattern (lower underestimation with restrictive, and higher with obstructive). CONCLUSIONS: The inclusion of algorithms that calculate the pressure loss as a function of the flow exiting the ventilator in commercial models may increase the reliability of $\mathbf{V}_{\mathbf{T}}$ estimation. Key words: noninvasive ventilation; tidal volume; leaks. [Respir Care 2013;58(5):770-777. (c) 2013 Daedalus Enterprises]
\end{abstract}

\section{Introduction}

Noninvasive ventilation (NIV) has proven to be an effective therapy for both acute and chronic respiratory fail-

Drs Luján, Sogo, Pomares, and Monsó are affiliated with the Department of Pneumology; and Dr Blanch is affiliated with the Critical Care Department. Corporació Sanitària Parc Taulí, Institut Universitari Parc Taulí, Universitat Autònoma de Barcelona, Sabadell, Spain. Mr Sales is affiliated with BetterCare, Sabadell, Spain. Drs Blanch, Monsó, and Luján are also affiliated with Centro de Investigación Biomédica en Red de Enfermedades Respiratorias.

This work was partly supported by grant AGAUR (VALOR 2010-00188) from Centro de Investigación Biomédica en Red de Enfermedades Respiratorias and Fundació Parc Taulí 2010. Dr Blanch has disclosed a relationship with BetterCare, Sabadell, Spain. The other authors have disclosed no conflicts of interest. ure. ${ }^{1}$ The portable ventilators currently available provide adequate treatment for these clinical situations and are relatively easy to use. As a result, their use has extended from ICUs to hospital wards and even to patients' homes. Thus, the number of patients receiving domiciliary NIV in the last 20 years has increased considerably all over Europe. ${ }^{2}$

In clinical practice, ventilation mode and parameters are defined by the physician or respiratory therapist, based on

\footnotetext{
Correspondence: Manel Luján MD PhD, Department of Pneumology, Corporació Sanitària Parc Taulí, Institut Universitari Parc Taulí, Universitat Autònoma de Barcelona, Parc Tauli 1, Sabadell 08202 Spain. Email: mlujan@tauli.cat.
}

DOI: $10.4187 /$ respcare. 02010 


\section{Effect of Leak and Breathing Pattern on the Accuracy of Tidal Volume Estimation}

underlying pathology, the patient's tolerance of the ventilation pattern, and the improvement attained in arterial blood gases. ${ }^{3,4}$ In some cases, however, the patient does not achieve the desired improvement, and additional monitoring of the interactions between patient and ventilator are required. Certain ventilators have recently incorporated commercial software (built-in software) that provides information on variables such as pressure and flow, also allowing download of data stored in the internal memory for later analysis. These data, however, must be validated before they can be considered for use in clinical practice, since ventilation mode, interface, type of tubing (single or double), and characteristics of the expiratory valve used (active or intentional leak) may affect the basic morphology of the graphs. 5,6

The built-in software of commercial ventilators should be able to measure accurately tidal volume $\left(\mathrm{V}_{\mathrm{T}}\right)$, even in conditions of increasing leak. A recent study ${ }^{7}$ found that currently available built-in software underestimates both leaks and mean $\mathrm{V}_{\mathrm{T}}$, without a clear-cut relationship between leak and accuracy of $\mathrm{V}_{\mathrm{T}}$ measurement. The purpose of the present study was to compare the $\mathrm{V}_{\mathrm{T}}$ values calculated by built-in software of a wide range of commercial ventilators with $\mathrm{V}_{\mathrm{T}}$ measured by a calibrated pneumotachograph breath to breath, in bench simulation conditions under increasing values of controlled leak, to determine whether the incorporation of a mathematical algorithm that computes leak-related pressure losses through the tubing during breathing may improve the reliability of the $\mathrm{V}_{\mathrm{T}}$ measure estimated by built-in software.

\section{Methods}

\section{Study Design}

The experiment was conducted under simulation conditions in a mechanical ventilation laboratory equipped with a breathing simulator (SB2000, Ingmar Medical, Pittsburgh, Pennsylvania) that was used to test the ventilators. This lung simulator allows active inspiration with different levels of pressure and duration of inspiratory effort, and is able to modify the parameters of lung mechanics through system changes in compliance and resistance. As a signal acquisition system, an external polygraph (Powerlab 16Sp, ADInstruments, Sydney, Australia), equipped with a pressure transducer (model 1050, ADInstruments, Sydney, Australia), and a pneumotachograph (model S300, instrumental dead space $70 \mathrm{~mL}$, resistance $0.0018 \mathrm{~cm} \mathrm{H}_{2} \mathrm{O} / \mathrm{L} / \mathrm{s}$, ADInstruments, Sydney, Australia) was used. Sampling frequency was set to $200 \mathrm{~Hz}$, and the polygraph was connected to a computer equipped with data acquisition software (Chart 5.0, ADInstruments, Sydney, Australia). To avoid the influence of uncontrolled leaks, commercial NIV interfaces (nasal or oronasal masks) between the ventilator

\section{QUICK LOOK}

\section{Current knowledge}

Noninvasive ventilation (NIV) is commonly delivered using pressure support ventilation with a circuit with a known leak. The ventilator estimates the tidal volume delivered to the patient, but the accuracy of that estimate in the face of varying leak is unknown.

\section{What this paper contributes to our knowledge}

The software of the tested NIV ventilators underestimated the actual tidal volume, and the greater the leak, the greater the difference between the estimated and actual tidal volume. An algorithm that compensated for the difference between the estimated leak measured at the distal and proximal sides of the circuit improved the accuracy.

and the simulator were not used, and the ventilator was directly connected to the simulator through standard 2-m tubing. A unidirectional valve with variable opening was interposed in the tubing and connected to a T-piece, to simulate continuous variable leaks between the ventilator and the simulator, and a second pneumotachograph was placed at the end of this valve to measure leak flow (Fig. 1).

\section{Calibration}

Before each session, both the pneumotachograph and the pressure transducer were calibrated following the manufacturer's instructions, using a 3-L syringe and against a water column, respectively. The measurements of the system with a 3 -L syringe showed an error of about $1 \%$, displaying values between $2,970 \mathrm{~mL}$ and $3,030 \mathrm{~mL}$ with the syringe.

\section{Leak Levels}

The ventilators were tested with 4 predetermined, calibrated leak flows $(35,45,55$, and $65 \mathrm{~L} / \mathrm{min})$ on CPAP of $20 \mathrm{~cm} \mathrm{H}_{2} \mathrm{O}$. The leak level was assessed before each step and using each tested ventilator. This range was selected because it includes the values provided by all the manufacturers as estimated leak flows for the interfaces used in the clinical setting. Thus, a leak of about $35 \mathrm{~L} / \mathrm{min}$ at a $20 \mathrm{~cm} \mathrm{H}_{2} \mathrm{O}$ of pressure corresponds to a small nasal mask, and a leak of over $60 \mathrm{~L} / \mathrm{min}$ corresponds to oronasal masks. ${ }^{8,9}$

\section{Pulmonary Mechanics}

For each leak level 3 different conditions of lung mechanics in the breathing simulator were programmed ${ }^{10}$ : 


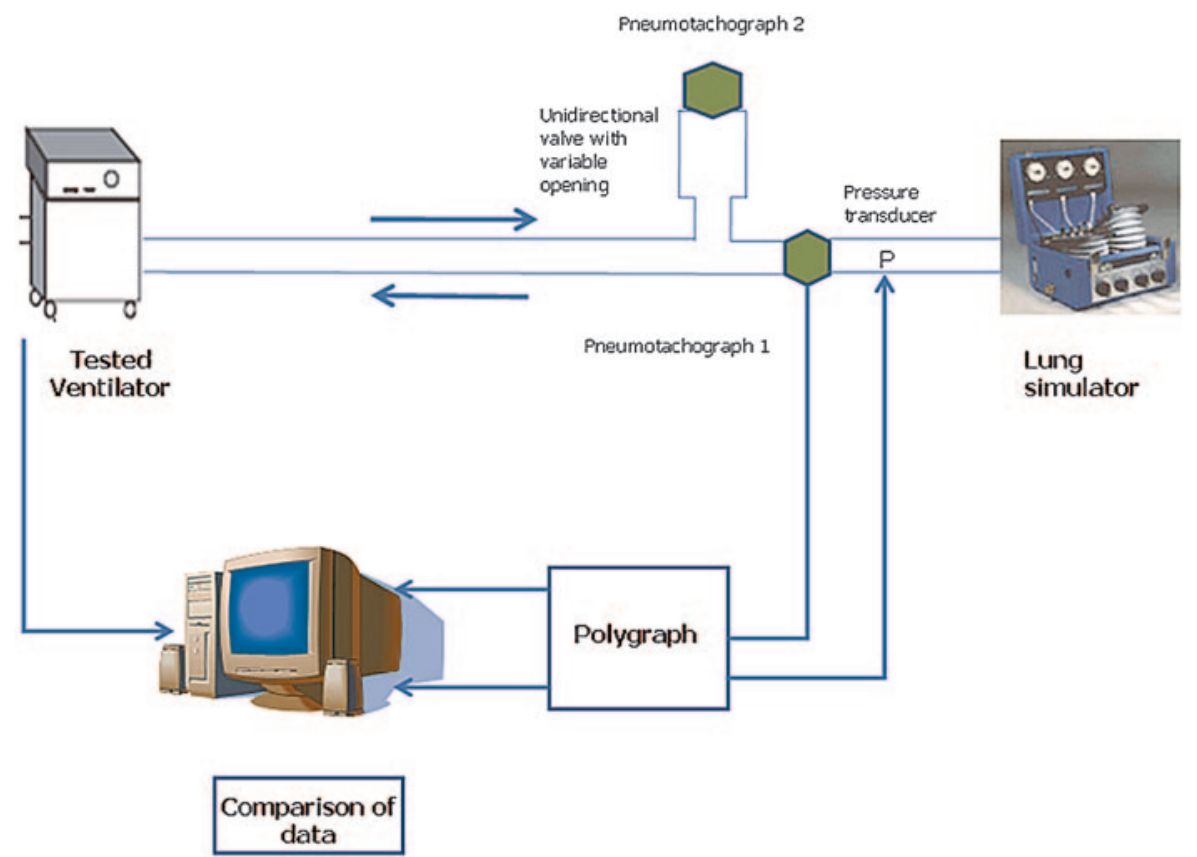

Fig. 1. Design of the experimental conditions.

- Normal: compliance $60 \mathrm{~mL} / \mathrm{cm} \quad \mathrm{H}_{2} \mathrm{O}$, resistance $7.5 \mathrm{~cm} \mathrm{H}_{2} \mathrm{O} / \mathrm{L} / \mathrm{s}$

- Obstructive: compliance $60 \mathrm{~mL} / \mathrm{cm} \mathrm{H}_{2} \mathrm{O}$, resistance $25 \mathrm{~cm} \mathrm{H}_{2} \mathrm{O} / \mathrm{L} / \mathrm{s}$

- Restrictive: compliance $30 \mathrm{~mL} / \mathrm{cm}_{2} \mathrm{O}$, resistance $7.5 \mathrm{~cm} \mathrm{H}_{2} \mathrm{O} / \mathrm{L} / \mathrm{s}$

\section{Parameters in the Tested Ventilators}

For each level of leakage and ventilation pattern, 3 different levels of pressure support (PS) were programmed:

- $5 \mathrm{~cm} \mathrm{H}_{2} \mathrm{O}$ : inspiratory pressure $10 \mathrm{~cm} \mathrm{H}_{2} \mathrm{O}$, expiratory pressure $5 \mathrm{~cm} \mathrm{H}_{2} \mathrm{O}$

- $10 \mathrm{~cm} \mathrm{H} \mathrm{H}_{2} \mathrm{O}$ : inspiratory pressure $15 \mathrm{~cm} \mathrm{H}_{2} \mathrm{O}$, expiratory pressure $5 \mathrm{~cm} \mathrm{H}_{2} \mathrm{O}$

- $15 \mathrm{~cm} \mathrm{H} \mathrm{H}_{2} \mathrm{O}$ : inspiratory pressure $20 \mathrm{~cm} \mathrm{H}_{2} \mathrm{O}$, expiratory pressure $5 \mathrm{~cm} \mathrm{H}_{2} \mathrm{O}$.

Other parameters were fixed as follows. Rise time was set at an intermediate value $(200 \mathrm{~ms})$, and the cycle-off criterion was at $30 \%$ of peak flow. Inspiratory trigger was set at a maximum effort with each ventilator to avoid auto-triggering. Spontaneous breathing frequency was programmed in the simulator at 10 breaths/min, with an effort level of $50 \%$ of the maximum allowed by the simulator, corresponding to a measured peak flow of $49.2 \mathrm{~L} / \mathrm{min}$, and 1 second duration of effort.

\section{Ventilators Tested}

Five ventilators from 4 different manufacturers with their commercial built-in software were tested:

- Vivo 50, Breas Medical/GE Healthcare, Mölnycke, Sweden, firmware 1.3, built-in software Vivo 50-PC 2.0. The accuracy of the measured $\mathrm{V}_{\mathrm{T}}$ with intentional leakage is $\pm 20 \%$, and the conversion factor to body temperature and pressure saturated (BTPS) is ambient temperature and pressure dry (ATPD) $+10 \%$.

- Puritan Bennett 560 (PB560), Covidien, Mansfield, Massachusetts, built-in software Respiratory Insight 2.1. The accuracy of the measured $\mathrm{V}_{\mathrm{T}}$ with intentional leakage is $\pm 10 \%$, and the conversion factor to BTPS is ATPD $+10 \%$.

- Trilogy 100, Philips Respironics, Murrysville, Pennsylvania, built-in software DirectView. The accuracy of the measured $\mathrm{V}_{\mathrm{T}}$ with intentional leakage is $\pm 15 \%$, and the conversion factor to BTPS is ATPD $+12 \%$.

- Stellar 100, ResMed, San Diego, California, built-in software ResScan 3.14. The accuracy of the measured $\mathrm{V}_{\mathrm{T}}$ with intentional leakage is $\pm 15 \%$, and data about volume are displayed in ATPD conditions.

- Modified Vivo 50, Breas-General Electric, Mölnycke, Sweden, firmware 2.0, which includes a mathematical algorithm designed for the correction of the pressure value at the end of tubing, in accordance with the flow circulating through the ventilator pneumotachograph and the values calculated for the resistance. 


\section{Effect of Leak and Breathing Pattern on the Accuracy of Tidal Volume Estimation}

These ventilators were selected due to their implementation in Europe, and because they had built-in software that allowed the analysis breath by breath of estimated $\mathrm{V}_{\mathrm{T}}$ values.

\section{Cycle to Cycle $V_{T}$ Comparison}

Each experimental condition was maintained for 3 minutes, and only the last 10 breaths (last minute) were analyzed, to ensure the stability of the system across the modification of settings (increasing leak, mechanical pattern and pressure level). The $\mathrm{V}_{\mathrm{T}}$ values of the last 10 breaths were compared breath to breath, taking the highest value of the volume-time curve both from the commercial software registration and from the external pneumotachograph. The externally acquired volume-time curve was obtained by integration of the flow-time curve in each cycle, restarting the integral when the flow value crossed the zero point toward positive values. If the volume-time curve of the external acquisition system presented any deviation before the initiation of the inspiratory cycle, causing the zero volume point not to coincide with the point of zero flow, a second reinitiating criterion was selected, based on the transition to inspiratory pressure in the pressure-time graph. For the Trilogy 100 and Stellar 100, which do not display volume-time curves, we took the value provided by the software after each cycle.

\section{Conversion to BTPS Conditions}

To standardize the analysis of true $\mathrm{V}_{\mathrm{T}}$ entering into the respiratory system, the $\mathrm{V}_{\mathrm{T}}$ obtained by the pneumotachograph was converted to BTPS conditions ${ }^{11}$ by applying the following formula:

$\mathrm{V}_{\mathrm{T}}(\mathrm{BTPS})=\mathrm{V}_{\mathrm{T}}(\mathrm{ATPD}) \times($ barometric pressure water vapor pressure/barometric pressure -47$) \times 310 /$ $\left(273+\right.$ temperature in $\left.{ }^{\circ} \mathrm{C}\right)$

where 47 is the vapor pressure of $\mathrm{H}_{2} \mathrm{O}$ at $37^{\circ} \mathrm{C}, 273$ is the temperature in Kelvin scale corresponding to $0^{\circ} \mathrm{C}$, and 310 is the value in degrees Kelvin at body temperature. Given that the ambient temperature at which the study was performed was $20^{\circ} \mathrm{C}$ and the vapor pressure of $\mathrm{H}_{2} \mathrm{O}$ at that temperature is $17.5 \mathrm{~mm} \mathrm{Hg}$, substituting the values, the conversion of ATPD to BTPS increased $\mathrm{V}_{\mathrm{T}}$ an average of $10.2 \%$.

\section{Exclusion of Measurements}

The cycles were discarded when excessive leakage of the circuit induced auto-trigger.
Table. Difference Between Displayed and Measured Tidal Volume With Ventilators

\begin{tabular}{lcccc}
\hline \hline \multicolumn{1}{c}{ Ventilator } & $\begin{array}{c}\text { Difference, } \\
\mathrm{mL}\end{array}$ & $\begin{array}{c}\text { Difference, } \\
\%\end{array}$ & $\begin{array}{c}\text { Intraclass } \\
\text { Correlation } \\
\text { Coefficient }\end{array}$ & $P$ \\
\hline Vivo 50 & $-84 \pm 25$ & $-14.7 \pm 3.3$ & 0.96 & $<.001$ \\
PB560 & $-59 \pm 36$ & $-12.6 \pm 4.5$ & 0.98 & $<.001$ \\
Trilogy 100 & $-41 \pm 46$ & $-7.8 \pm 6.9$ & 0.97 & $<.001$ \\
Stellar 100 & $-36 \pm 55$ & $-7.1 \pm 9.9$ & 0.95 & $<.001$ \\
Modified Vivo 50 & $-22 \pm 9$ & $-3.6 \pm 1.5$ & 0.99 & $<.001$ \\
\hline
\end{tabular}

\section{Statistical Analysis}

Values for each experimental condition are expressed as mean \pm SD. First, differences between $V_{T}$ values provided by the built-in software and the external system were calculated and expressed as absolute values (in $\mathrm{mL}$ ) and as a percentage of the externally measured $\mathrm{V}_{\mathrm{T}}$, considered as the reference for the purposes of the study, according to the following formula:

$\left(\mathrm{V}_{\mathrm{T}}\right.$ ventilator $-\mathrm{V}_{\mathrm{T}}$ pneumotachograph $) \times 100 / \mathrm{V}_{\mathrm{T}}$ pneumotachograph

Paired values of $\mathrm{V}_{\mathrm{T}}$ were compared by analysis of variance, with Bonferroni post hoc analysis. A reliability analysis using the intraclass correlation coefficient for individual measures was performed for each tested ventilator and predetermined leakage. ${ }^{12}$ Second, a multivariate linear regression analysis was performed for each tested ventilator, considering the accuracy of the $\mathrm{V}_{\mathrm{T}}$ estimation by the built-in software of the ventilator as the outcome, and introducing in the model all values with $P<.10$ in the univariate analysis as covariates. The percentage of the difference from the reference in the displayed $\mathrm{V}_{\mathrm{T}}$ was selected as a dependent variable. Categorical variables (ventilatory pattern, leaks, and pressure level) were recoded into ordinal variables, with the reference categories being the lowest value of leak $(35 \mathrm{~L} / \mathrm{min})$, pressure $\left(5 \mathrm{~cm} \mathrm{H}_{2} \mathrm{O}\right)$, and the restrictive breathing pattern for each ventilator. Results are expressed as mean difference changes for each experimental step and $95 \%$ confidence intervals. The significance level was set at $P<.05$. Statistical analysis was performed using statistics software (SPSS 19, SPSS, Chicago, Illinois).

\section{Results}

Paired values of $\mathrm{V}_{\mathrm{T}}$ were compared breath to breath for all the conditions mentioned, with up to 1,800 cycles analyzed. As the Table shows, all the ventilators underesti- 


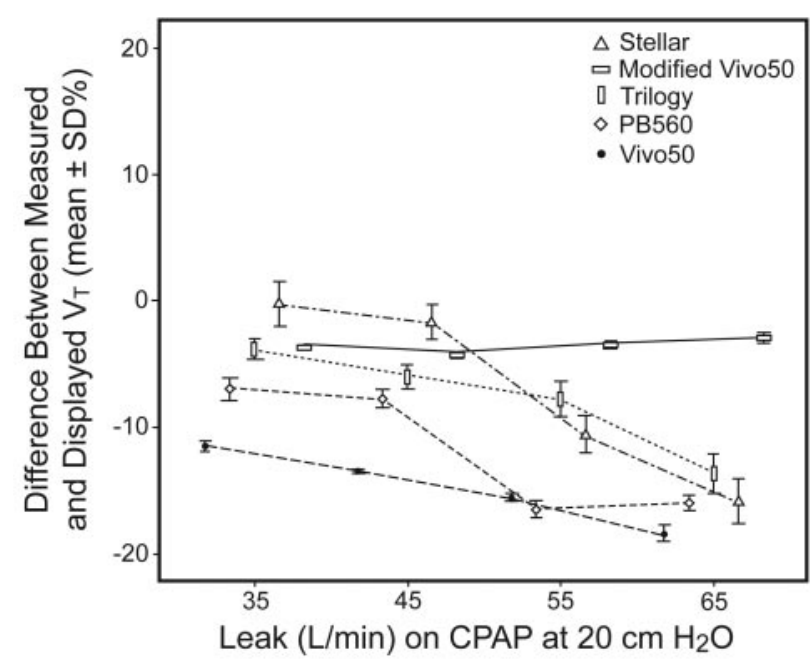

Fig. 2. Influence of level of leak in the difference between measured and displayed values in the built-in software of the 5 ventilators studied. The amount of leak is measured at CPAP of $20 \mathrm{~cm} \mathrm{H} \mathrm{H}_{2}$.

mated $\mathrm{V}_{\mathrm{T}}$ measured by the pneumotachograph, the underestimation ranging between $-21.7 \pm 9.5 \mathrm{~mL}$ and $-83.5 \pm 25.3 \mathrm{~mL}$, corresponding to $-3.6 \pm 1.5 \%$ and $-14.7 \pm 3.25 \%$ of the externally measured $\mathrm{V}_{\mathrm{T}}$. All ventilators showed reliabilities ranging between 0.90 and 0.99 : the most reliable was the modified Vivo 50, with an intraclass correlation coefficient value of 0.99 .

Regarding the differences in real delivered $\mathrm{V}_{\mathrm{T}}$, we did not find any statistically significant differences between the increasing leak levels for any ventilator (analysis of variance). The mean differences found between the lowest $(35 \mathrm{~L} / \mathrm{min})$ and the highest leak $(65 \mathrm{~L} / \mathrm{min})$ were: $28 \pm 13.75 \mathrm{~mL}$ for Vivo 50, $16.97 \pm 27.4 \mathrm{~mL}$ for Trilogy, and $48.6 \pm 28.05 \mathrm{~mL}$ for Stellar 100. Interestingly, negative differences (higher delivered $\mathrm{V}_{\mathrm{T}}$ in the steps with highest leak) were found in the other 2 ventilators, indicating a certain degree of overcompensation of the leak: the mean differences were $-14 \pm 30.73 \mathrm{~mL}$ for the PB560 and $-33.48 \pm 26.55 \mathrm{~mL}$ for the modified Vivo 50 .

\section{Influence of Incremental Values of Leakage}

All ventilators except one (the modified Vivo 50) showed a direct relationship between leak and underestimation, both in absolute values in $\mathrm{mL}$ and in percentage of the externally measured $\mathrm{V}_{\mathrm{T}}$. Figure 2 displays the graphic representation of the percentage of $\mathrm{V}_{\mathrm{T}}$ deviation for each ventilator and each level of leak. At the lowest leak (35 L/ min on CPAP at $20 \mathrm{~cm} \mathrm{H}_{2} \mathrm{O}$ ), corresponding to a nasal mask in clinical practice, significant differences were found between values displayed by the different ventilators. The Stellar 100 ventilator was the one with least deviation in $\mathrm{V}_{\mathrm{T}}$ monitoring, with a mean underestimation of

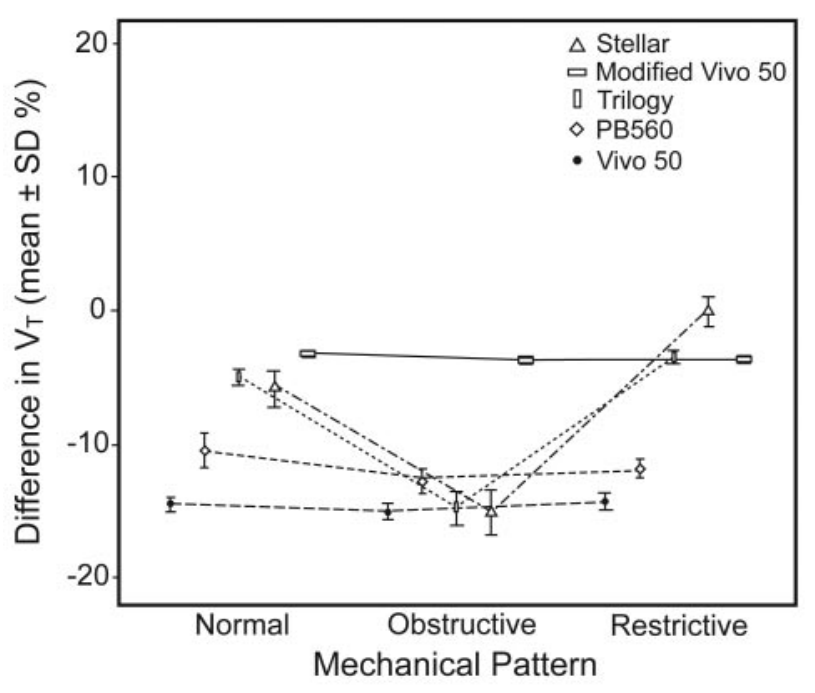

Fig. 3. Influence of mechanical pattern used in the simulator in the difference between measured values and displayed values in the built-in software of the 5 ventilators studied.

$5.6 \pm 45.3 \mathrm{~mL}$, corresponding to $-0.23 \pm 8.23 \%$ of the external $\mathrm{V}_{\mathrm{T}}$ values. Conversely, the Vivo 50 underestimated $\mathrm{V}_{\mathrm{T}}$ by $66.19 \pm 13.86 \mathrm{~mL}$, that is, by $11.51 \pm 1.81 \%$ of the external reference. An increase in the leak had the highest influence on the Stellar 100 ventilator, which showed an underestimation of $-23.65 \pm 2.26 \mathrm{~mL}$, corresponding to a $-5.56 \pm 0.36 \%$ deviation from the externally measured $\mathrm{V}_{\mathrm{T}}$ for each increase in the leak of $10 \mathrm{~L} /$ min (on CPAP at $20 \mathrm{~cm} \mathrm{H}_{2} \mathrm{O}, P<.001$ ). Conversely, the ventilator with the lowest effect of leakage on the estimation of $\mathrm{V}_{\mathrm{T}}$ was the modified Vivo 50, which showed an overestimation of $1.65 \pm 0.44 \mathrm{~mL}, 0.3 \pm 0.06 \%$ of the reference, for each increase in $10 \mathrm{~L} / \mathrm{min}$. These differences remained after controlling for the breathing pattern and level of PS: the mean degree of underestimation for each incremental leak value of $10 \mathrm{~L} / \mathrm{min}$ after adjusting for mechanical pattern and level of PS were $-2.27 \%$ (95\% CI -2.45 to -2.09 ) for Vivo $50,-2.82 \%$ (95\% CI -3.12 to -2.52 ) for PB560, $-3.06 \%$ (95\% CI -3.48 to -2.8 ) for Trilogy 100 , and $-5.42 \%$ (95\% CI 5.96 to -5.2 ) for Stellar 100. The modified Vivo 50, although still underestimating $\mathrm{V}_{\mathrm{T}}$, decreased the difference between displayed $V_{T}$ and measured $V_{T}$ for each $10 \mathrm{~L} / \mathrm{min}$ of incremental leak $(0.3 \%$ for each incremental leak value of $10 \mathrm{~L} / \mathrm{min}, 95 \%$ CI $0.17-0.43$ ).

\section{Influence of Breathing Pattern in the Accuracy of $V_{T}$ Estimation}

The PB560, Trilogy 100, and Stellar 100 showed significant differences according to the breathing pattern predetermined in the simulator (Fig. 3). In these ventilators 


\section{Effect of Leak and Breathing Pattern on the Accuracy of Tidal Volume Estimation}



Fig. 4. Influence of inflation pressures programmed in the ventilator in the difference (in percentage) between measured and displayed values in the built-in software of the 5 ventilators studied.

the restrictive pattern presented low underestimation, with the lowest percentage difference in the PB560 ventilator. The underestimation was higher when the respiratory pattern was obstructive in the Trilogy 100 ventilator, approaching $15 \%$ of the externally measured $\mathrm{V}_{\mathrm{T}}$, compared with 3-5\% for the restrictive pattern. Finally, in the Stellar 100 ventilator the 3 patterns presented major differences $(1.6 \%, 5 \%$, and $15 \%$ for the restrictive, normal, and obstructive breathing patterns respectively).

\section{Influence of Inflation Pressures}

All ventilators showed significant differences between displayed and externally measured $\mathrm{V}_{\mathrm{T}}$ in absolute values. Three ventilators showed an effect on the percentage of the reference $\mathrm{V}_{\mathrm{T}}$ when the pressure was increased. In the Vivo 50 ventilator the underestimation with PS $15 \mathrm{~cm} \mathrm{H}_{2} \mathrm{O}$ was $-15.62 \pm 3.7 \%$ of the externally measured $\mathrm{V}_{\mathrm{T}}$, compared with $-14.62 \pm 3.24 \%$ with PS $10 \mathrm{~cm} \mathrm{H}_{2} \mathrm{O}$, and $-13.94 \pm 2.52 \%$ with PS $5 \mathrm{~cm} \mathrm{H}_{2} \mathrm{O}(P<.001)$. For the Stellar 100 ventilator the values were $-9.36 \pm 11.1 \%$ for PS $15 \mathrm{~cm} \mathrm{H}_{2} \mathrm{O},-7.41 \pm 9.75 \%$ for PS $10 \mathrm{~cm} \mathrm{H}_{2} \mathrm{O}$, and $-4.41 \pm 8.24 \%$ for PS $5 \mathrm{~cm} \mathrm{H}_{2} \mathrm{O}$, respectively $(P<.001)$. Conversely, in the modified Vivo 50 the underestimation was lower with higher inflation pressures $(-3.09 \pm 4.53 \%$ for PS $15 \mathrm{~cm} \mathrm{H}_{2} \mathrm{O},-3.52 \pm 3.21 \%$ for PS $10 \mathrm{~cm} \mathrm{H}_{2} \mathrm{O}$, and $-4.08 \pm 1.44 \%$ for PS $5 \mathrm{~cm} \mathrm{H}_{2} \mathrm{O}, P=.01$ ) (Fig. 4).

\section{Discussion}

In this NIV bench simulation model with single tubing and controlled leaks, significant differences in the accuracy of the $\mathrm{V}_{\mathrm{T}}$ estimation provided by the built-in software were found in the 5 commercial ventilators tested. All the devices underestimated $\mathrm{V}_{\mathrm{T}}$ to different degrees, mainly due to the increases in the controlled leaks. In some ventilators the underestimation reached values near $20 \%$ of the externally measured $V_{T}$ when the leaks were high. In 3 ventilators the underestimation was also influenced by the breathing pattern and was higher when the pattern was obstructive. Finally, and perhaps most importantly, the introduction of a mathematical algorithm in one ventilator that calculates the difference of estimated pressures between the distal and the proximal side of the tubing significantly improved the accuracy of the measurement of the software.

Few studies have compared data monitored by ventilators with those obtained through an external capture system. Lyazidi and colleagues ${ }^{13}$ recently published data comparing displayed and real $\mathrm{V}_{\mathrm{T}}$ in continuous mandatory ventilation mode, obtained from 9 commercial ICU ventilators equipped with compensation algorithms that take into account the fact that part of the delivered volume is compressed in the circuit when the ventilator is working in volume control ventilation. The authors demonstrated clinically important differences between the 2 values, which differed from one ventilator to another. In some cases the error was as high as $17 \%$ of real $\mathrm{V}_{\mathrm{T}}$, a figure that was in accordance with our findings in pressure support mode.

In a bench model with an experimental design similar to the approach used in our study, Contal and colleagues. ${ }^{7}$ studied the correlation between displayed $\mathrm{V}_{\mathrm{T}}$ and leaks in 7 commercial ventilators, comparing these values with data obtained by an external system signal acquisition. Their results showed also a systematic underestimation of $\mathrm{V}_{\mathrm{T}}$, which ranged between 66 and $236 \mathrm{~mL}$, and increased with higher inflation pressures, but the underestimation was related to incremental leaks in only one ventilator, whereas in the present study this linear relationship was found in all ventilators but one.

To interpret the findings of our study it is necessary to bear in mind the modifications that are performed on the "native" waveforms captured by the pneumotachograph placed inside the ventilator by the built-in software. When systems with single tubing with intentional leak are used, the instantaneous total flow captured by the pneumotachograph during inspiration is the sum of the flow corresponding to $V_{T}$ plus the flow escaping through the valve. Accordingly, the equation to be applied is as follows:

$$
\dot{\mathrm{V}}_{\mathrm{pn}(\mathrm{i})}=\dot{\mathrm{V}}_{\mathrm{pat}(\mathrm{i})}+\dot{\mathrm{V}}_{\mathrm{ev}(\mathrm{i})}
$$

where $\dot{\mathrm{V}}_{\mathrm{pn}(\mathrm{i})}$ is the total flow captured by the pneumotachograph during the inspiratory phase, $\dot{\mathrm{V}}_{\text {pat(i) }}$ corresponds to the patient's flow, and $\dot{V}_{\text {ev(i) }}$ corresponds to the flow that simultaneously escapes through the valve. This second term has a linear behavior, and when the pressure is 

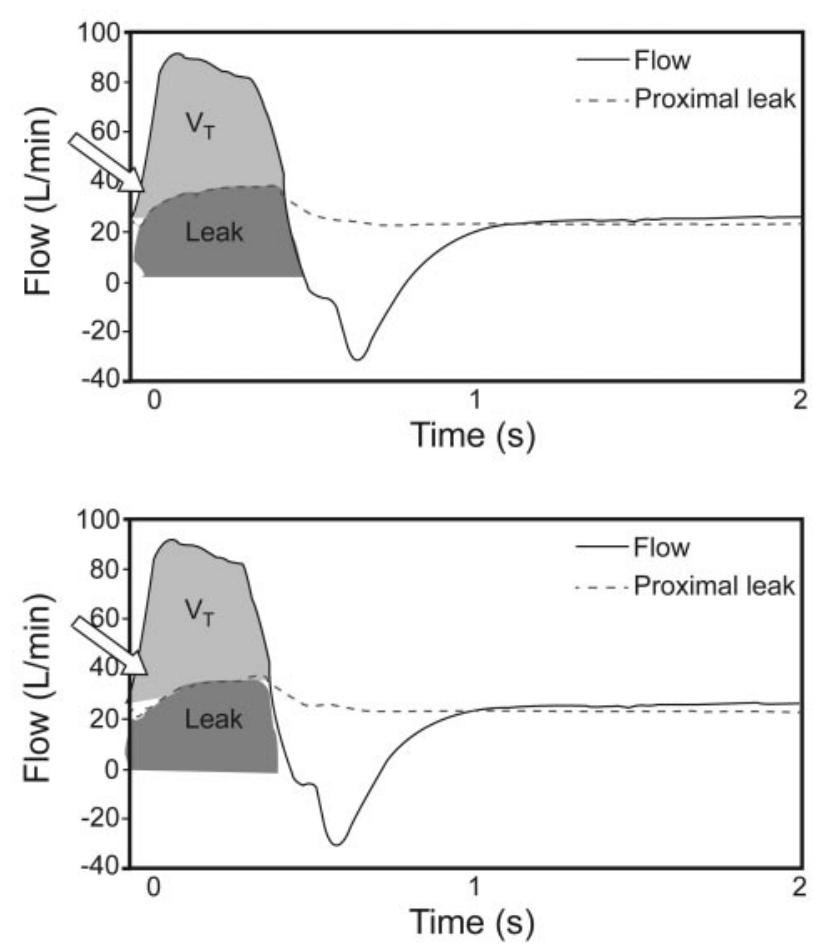

Fig. 5. Simulation of the calculation of inspired tidal volume $\left(\mathrm{V}_{\mathrm{T}}\right)$ using 2 models of leak computation. In the top panel, the calculation of leakage was performed according to the monitored pressure level at the output of the ventilator. In the lower panel, the calculation of leakage was calculated using the pressure graphic monitored at the end of a 2-meter tube. In both cases the equation used was equivalent to a leak of $45 \mathrm{~L} / \mathrm{min}$ on CPAP at $20 \mathrm{~cm} \mathrm{H}_{2} \mathrm{O}$ $($ leak $=1.57 \times$ pressure +15.1$)$. As a consequence, the $\mathrm{V}_{\mathrm{T}}$ is slightly larger in the lower panel; the white arrows point to the zone of difference, which is about $45 \mathrm{~mL}$ in this particular case.

higher, the leakage through the valve increases. In fact, the flow that escapes through the commercial valves operates in an almost linear pattern in the range of pressures between 4 and $20 \mathrm{~cm} \mathrm{H}_{2} \mathrm{O}$, the range we used in this study. This means that leakage through the valve may be estimated as a linear function of pressure, and so the equation can be transformed to:

$$
\dot{\mathrm{V}}_{\mathrm{pn}(\mathrm{i})}=\dot{\mathrm{V}}_{\mathrm{pat}(\mathrm{i})}+\left[\mathrm{A}\left(\mathrm{P}_{\mathrm{aw}}-\mathrm{P}_{\mathrm{atm}}\right)+\mathrm{B}\right](\mathrm{i})
$$

where $\mathrm{P}_{\mathrm{aw}(\mathrm{i})}$ is airway pressure, $\mathrm{P}_{\mathrm{atm}(\mathrm{i})}$ is atmospheric pressure, the term $\mathrm{P}_{\mathrm{aw}}-\mathrm{P}_{\mathrm{atm}}$ is the difference in pressure on either side of the valve, $\mathrm{A}$ is the coefficient of linear regression, and B is an independent term. This means that if the built-in software captures pressure inside the ventilator, the second term of the equation (leak) is overestimated, due to the loss of pressure through the tubing, which narrows the difference between the pressures inside the tubing and atmospheric pressure. Moreover, this loss of pressure is greater when the flow circulating through the pneumotachograph is larger (the Poiseuille law). Figure 5 illustrates the difference mentioned.

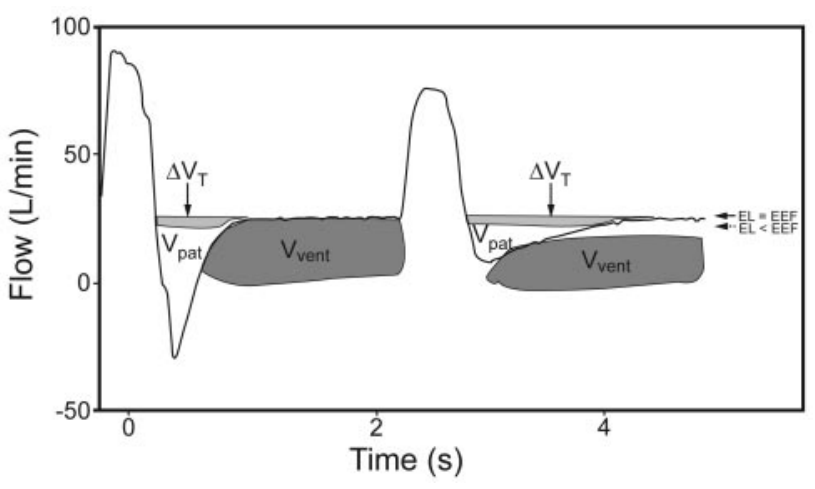

Fig. 6. Simulation of potential consequences of underestimation of leaks when expiratory tidal volume $\left(\mathrm{V}_{\mathrm{T}}\right)$ is monitored. If expiratory leaks are in agreement with end-expiratory flow (EL $=E E F$ line), the expiratory volume is accurately monitored. Conversely, if leaks are underestimated (EL $<E E F)$, or are monitored before the expiration is completed, for example in the presence of air trapping (end-expiratory flow $<0$ ), the volume of expired $V_{T}$ underestimated is greater in the second cycle (obstructive) than in the first (restrictive). $\dot{V}_{\text {pat }}=$ flow/volume corresponding to the patient's expiratory $V_{\mathrm{T}}$. $\mathrm{V}_{\text {vent }}=$ flow/volume corresponding to the expiratory leak. $\Delta \mathrm{V}_{\mathrm{T}}=$ difference of monitored $\mathrm{V}_{\mathrm{T}}$ when expiratory leak is underestimated.

The data for the Trilogy 100 ventilator should be analyzed separately, because it is the only ventilator in which the manufacturer states that expiratory $\mathrm{V}_{\mathrm{T}}$ is monitored. This situation is quite different from the systems that monitor inspiration, because when monitoring the inspiratory $\mathrm{V}_{\mathrm{T}}$ the total flow is directly captured by the pneumotachograph and the main problem is how to distribute it between estimated $\mathrm{V}_{\mathrm{T}}$ and leaks. With this approach the amount of expiratory leak cannot be monitored directly and must be estimated with the help of the expiratory flow curve. This approach is represented in the equation:

$$
\dot{\mathrm{V}}_{\mathrm{ev}(\mathrm{e})}=\dot{\mathrm{V}}_{\mathrm{pat}(\mathrm{e})}+\dot{\mathrm{V}}_{\mathrm{vent}(\mathrm{e})}
$$

where $\dot{V}_{\text {ev(e) }}$ is the total flow exiting through the expiratory valve during expiration, $\dot{\mathrm{V}}_{\text {pat(e) }}$ is the expiratory flow of the patient, and $\mathrm{V}_{\text {vent(e) }}$ represents the flow delivered by the ventilator to maintain expiratory pressure level and to compensate for leaks. In this setting, small underestimations of the total flow exiting through the valve might also cause underestimations of expiratory $\mathrm{V}_{\mathrm{T}}$. Moreover, these underestimations would be higher when expiratory resistance increases, due to 2 potential mechanisms. First, if the expiration is incomplete, the flow monitored at end-expiration may be lower than in a restrictive model. Second, the underestimated fraction of expired $\mathrm{V}_{\mathrm{T}}$ as a function of time would also be higher in an obstructive model. See Figure 6 for further details.

This model may explain some of the findings of the present study. In fact, the correction of the instantaneous 


\section{Effect of Leak and Breathing Pattern on the Accuracy of Tidal Volume Estimation}

pressure graph with a mathematical algorithm that takes this approach into account in one of the ventilators examined improved the accuracy of the estimated $\mathrm{V}_{\mathrm{T}}$ measurement in our study. The influence of ventilatory pattern on this estimation may be accounted for by the same hypothesis, under the assumption that the increased elastance of the system will shorten the inspiratory time.

The results of this study have important implications for clinical practice. If we consider that there may be differences of up to $20 \%$ in the controlled leak between the different commercial interfaces, this means that, even with a perfectly fitted mask, $V_{T}$ estimation provided by the built-in software will be more underestimated when a facial mask is used by the patient. Furthermore, a systematic underestimation of $\mathrm{V}_{\mathrm{T}}$ can induce the clinician to increase the support, which may worsen the patient's lung hyperinflation. Finally, the highest level of leakage used in our study is not far from what may be found with a standard facial mask. Then the underestimation of $\mathrm{V}_{\mathrm{T}}$ with higher leaks would be $>25-30 \%$ of the $\mathrm{V}_{\mathrm{T}}$.

The present study has some limitations. We tested 5 ventilators; the proposed correction of the algorithm may not be applicable to all commercial ventilators, and even some differences in the estimated values might be found between different units of the same brand and model. Additionally, in this model, leaks were considered as a linear variable, whereas in clinical practice there are certain situations (eg, poorly fitting mask, and expiration through the mouth in a patient wearing a nasal interface) in which the behavior of leaks may be nonlinear, as pointed out by Oliveri et al. ${ }^{10}$ Finally, our ventilation model is simpler than those designed and used by other authors, because we decided to avoid the interference of undetected additional leaks that more complex models might have produced.

\section{Conclusions}

In summary, this bench simulation model showed that the built-in software of commercial ventilators underestimates real $\mathrm{V}_{\mathrm{T}}$, with increasing leakage as the main factor that influences this effect. The introduction of a mathematical algorithm in one ventilator, which compensates for the difference between the estimated leaks measured at the distal and proximal sides of the tubing, significantly improved the accuracy of the measurements.

\section{ACKNOWLEDGMENTS}

We thank Michael Maudsley for revision of the English version of the manuscript.

\section{REFERENCES}

1. Brochard L. Mechanical ventilation: invasive versus non-invasive. Eur Respir J 2003;22(Suppl 47):31S-37S.

2. Lloyd-Owen SJ, Donaldson GC, Ambrosino N, Escarabill J, Farre R, Fauroux B, et al. Patterns of home mechanical ventilation use in Europe: results from the Eurovent survey. Eur Respir J 2005;25(6): 1025-1031.

3. Elliott MW. Non-invasive ventilation during sleep: time to define new tools in the systematic evaluation of the technique. Thorax 2011;66(1):82-84.

4. Gonzalez-Bermejo J, Perrin C, Janssens JP, Pepin JL, Mroue G, Léger P, et al. Proposal for a systematic analysis of polygraphy or polysomnography or identifying and scoring abnormal events occurring during non-invasive ventilation. Thorax 2012;67(6):546-552.

5. Janssens JP, Borel JC, Pépin JL; SomnoNIV group. Nocturnal monitoring of home non-invasive ventilation: the contribution of simple tools such as pulse oximetry, capnography, built-in ventilator software and autonomic markers of sleep fragmentation. Thorax 2011; 66(5):438-445

6. Rabec C, Rodenstein DO, Leger P. Ventilator modes and settings during non-invasive ventilation: effects on respiratory events and implications for their identification. Thorax 2011;66(2):170-178.

7. Contal O, Vignaux L, Combescure C, Pepin JL, Jolliet P, Janssens JP. Monitoring of non-invasive ventilation by built-in software of home bi-level ventilators: a bench study. Chest 2012;141(2):469476.

8. Philips Respironics. Intentional leak rates for masks and exhalation ports. http://www.healthcare.philips.com/asset.aspx?alt=\&p=http:// www.healthcare.philips.com/pwc_hc/main/homehealth/sleep/masks/ pdf/Intentional_leak_rates_for_masks_and_exhalation ports_20111027.pdf. Accessed March 1, 2013.

9. ResMed. [Technical specifications of masks]. http://www.resmed. com/assets/documents/service_support/mask_technical_specs/ 1013116_asks-tech-specs_glo_spa.pdf. Article in Spanish. Accessed March 1, 2013.

10. Oliveri C, Costa R, Conti G, Navalesi P. Bench studies evaluating devices for non-invasive ventilation: critical analysis and future perspectives. Intensive Care Med. 2012;38(1):160-167.

11. Brown SP, Miller WC, Eason JM. Ergometry and calorimetry: the measurement of work and energy. In: Brown SP, Miller WC, Eason JM. Exercise physiology: basis of human movement in health and disease. Baltimore: Lippincott Williams \& Wilkins; 2006:98-126.

12. Prieto L, Lamarca L, Casado A, Alonso J. The evaluation of agreement on continuous variables by the intraclass correlation coefficient. J Epidemiol Community Health 1997;51(5):579-581.

13. Lyazidi A, Thille AW, Carteaux G, Galia F, Brochard L, Richard JC. Bench test evaluation of volume delivered by modern ICU ventilators during volume-controlled ventilation. Intensive Care Med 2010;36(12):2074-2080.

This article is approved for Continuing Respiratory Care Education credit. For information and to obtain your CRCE

(free to AARC members) visit

www.rcjournal.com

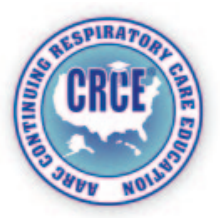

